\title{
Involvement of Gas7 in Nerve Growth Factor-Independent and Dependent Cell Processes in PC12 Cells
}

\author{
Chuck C.-K. Chao, ${ }^{1}$ L.-J. Su, ${ }^{1}$ N.-K. Sun, ${ }^{1}$ Y.-T. Ju, ${ }^{2}$ Jason C.-J. Lih, ${ }^{2}$ and \\ Sue Lin-Chao ${ }^{2 \star}$ \\ ${ }^{1}$ Tumor Biology Laboratory, Department of Biochemistry, Chang Gung University, Taoyuan, Taiwan \\ ${ }^{2}$ Institute of Molecular Biology, Academia Sinica, Taipei, Taiwan
}

Gas7, a growth arrest-specific gene originally isolated from serum-starved mouse fibroblast cells, is expressed in vivo predominantly in the brain and is required for neurite formation in cultured mouse cerebellar neurons (Ju et al. [1998] Proc. Natl. Acad. Sci. USA 95: 1142311428). Here we report that Gas7 plays a key role in the morphological differentiation of PC12 preneuronal rat pheochromocytoma cells (PC12 cells). We found that overexpression of murine Gas7 in PC12 cells leads to an expanded cell morphology and promotes spike-like cell processes that resemble the early stages of neurite formation. These processes undergo elongation upon addition of nerve growth factor (NGF). We also found that the addition of NGF induces the production of endogenous rat-Gas7 (rGas7), which is transiently elevated prior to the appearance of NGF-promoted neurite outgrowths. Furthermore, inhibition of endogenous rGas7 production by antisense nucleotides complimentary to the translation initiation region of a rGas7 cDNA (AJ131902) reduces the NGF-promoted neurite outgrowths. Our results demonstrate that Gas7 by itself influences early cell morphological development and likely functions as an early-stage intermediary in NGF-induced neuronal differentiation of PC12 culture cells. ๑ 2003 Wiley-Liss, Inc.

Key words: cell processes; Gas7; growth arrest-specific gene; neurite outgrowth; PC12 cells

Growth-arrest-specific (Gas) genes (Ju et al. 1998), originally isolated from mouse NIH3T3 fibroblasts, are expressed at a high level during cell growth arrest upon serum deprivation and contact inhibition resulting from cell confluence (Schneider et al., 1988; Brenner et al., 1989; Lih et al., 1996). In vivo, Gas gene expression has been observed during the growth arrest that accompanies terminal differentiation of cells during the development of peripheral nerves (Adlkofer et al., 1995; Magyar et al., 1996) and central nervous system neurons (Ju et al., 1998). Individual Gas genes have been implicated in a variety of biological functions, including the control of microfilament organization (Brancolini et al., 1992), nerve cell growth or differentiation (Manfioletti et al., 1990;
Adlkofer et al., 1995; Zoidl et al., 1995; Li et al., 1996; Ju et al., 1998), apoptosis (Fabbretti et al., 1995), and negative (Del Sal et al., 1994) and positive (Lih et al., 1996; Li et al., 1996) control of cell cycling. However, no sequence similarity or common structural features have been found among these genes.

Gas 7 is expressed selectively in neuronal cells of the mature cerebral cortex, hippocampus, and cerebellum (Ju et al., 1998). Inhibition of Gas 7 production in terminally differentiated cultures of embryonic mouse cerebellum impedes neurite outgrowths from maturing Purkinje cells (Ju et al., 1998), whereas Gas7 overexpression in undifferentiated neuroblastoma cell cultures dramatically promotes neurite outgrowths (Ju et al., 1998). These results suggest that Gas7 may be required for the formation of neurites from differentiating neurons.

PC12, a preneuronal cell line derived from rat adrenal pheochromocytoma, has been commonly used as a model system for studying neuronal differentiation (Green and Tischler, 1976). Upon treatment with nerve growth factor (NGF), PC12 cells undergo differentiation, cellular neurite outgrowths providing unique and obvious morphological changes characteristic of neuronal cell differentiation. In this study, in addition to isolating and characterizing the rat cDNA homologue of Gas 7, we investigated whether Gas7 plays a role in the differentiation of PC12 cells. We found that overproduction of a mouse Gas7-enhanced green fluorescent protein (EGFP) fusion protein in the absence of NGF was sufficient to promote spike-like cell projections in PC12 cells. These projections were further enhanced with the addition of NGF. Examination of endogenous rGas7 in PC12 cells revealed that NGF treatment sharply induced the rGas7. Inhibition of rGas7 production via antisense knockout

The nucleotide sequences reported in the paper have been submitted to the GenBank database under GenBank Accession Number AJ131902.

$\star$ Correspondence to: Sue Lin-Chao, Institute of Molecular Biology, Academia Sinica, Taipei, 11519, Taiwan. E-mail: mbsue@ccvax.sinica.edu.tw Received 12 May 2003; Revised 23 June 2003; Accepted 27 June 2003 
interfered with neurite outgrowth formation in PC12 cells. These results indicate that Gas7 plays a key role at an early stage of cell process development in cells other than cerebellar neurons and is necessary for neurite outgrowth formation during NGF-promoted PC12 differentiation.

\section{MATERIALS AND METHODS}

\section{Overexpression of mGas7-EGFP in PC12 Cells}

The mGas7-EGFP fusion was expressed using the cytomegalovirus (CMV) promoter in pEGFP-N1 (Clontech Laboratories, Inc., Palo Alto, CA) and was constructed by ligation of polymerase chain reaction (PCR)-amplified DNA containing full-length mouse Gas7 (Ju et al., 1998) into the EcoRI and KpnI cleavage sites of the vector. The resulting construct was named pmGas7-EGFP. The sequences of EcoRI and KpnI were included in the forward and reverse primers used for Gas 7 DNA amplification. DNA sequences encoding the mGas7-EGFP region were partially confirmed by DNA sequence analysis.

PC12 cells were maintained according to the supplier's instructions (American Type Culture Collection, Bethesda, $\mathrm{MD})$ and were grown to $50-70 \%$ confluence on coverslips and transfected with pmGas7-EGFP using Gibco BRI (Grand Island, NY). Lipofectamine reagent. Twenty-four hours after transfection, cells were induced to differentiate by addition of NGF for $48 \mathrm{hr}$. Overexpressed mGas7-EGFP cells were examined under a laser scanning confocal microscope (LSM 510; Zeiss). An identical experiment conducted in the absence of NGF treatment was also performed to assess the role of Gas7 in NGF-independent cell processes of PC12 cells.

\section{Immunofluorescence Detection of Endogenous rGas7 in PC12 Cells}

Differentiation of PC12 cells was stimulated by NGF (Upstate Biotechnology Inc., Lake Placid, NY; catalog No. 01-170; $50 \mathrm{ng} / \mathrm{ml}$ culture) in freshly split overnight cultures, grown on poly-L-lysine-precoated microscopic glass coverslips for various periods. Production of endogenous rGas7 was detected by immunofluorescence staining using anti-mouse Gas7 antiserum as described previously (Ju et al., 1998).

\section{Cloning and Sequencing of rGas7 cDNA}

rGas 7 cDNA was isolated by screening a rat brain (neocortex) expression library constructed in $\lambda \mathrm{ZAP}$ (II) (Stratagene, La Jolla, CA) using mouse Gas 7 as a probe. Cloned sequences were determined by automated DNA sequencing (for a fulllength cDNA sequence, 6,412 nucleotides (nt); see GenBank accession No. AJ131902). Gas7-hybridizable DNA fragments included a $2.1-\mathrm{kb} 5^{\prime}$-end fragment (nt 514-2,489) and a $3.8-\mathrm{kb}$ 3 '-end fragment (nt 2,610-6,412). A 287-nt DNA between the two fragments was isolated by PCR (Saiki et al., 1988) using a forward primer (5'-ATG TGC AGA GTC TCA TGG CTG TAG G-3', nt 2,421-2,445) and a reverse primer (5'-GCT GCC CAA AGG TCC AAG ATT AGT A-3', nt 2,683$2,707)$. The $5^{\prime}$-end upstream of the $2.1-\mathrm{kb}$ fragment was isolated from rat brain tissue by rapid amplification of cDNA ends (RACE; Frohman, 1990), using an anchor primer (5'-CCA TCC TAA TAC GAC TCA CTA TAG GGC-3'; Clontech, Palo Alto, CA) and a gene-specific primer (5'-CGA TGT GGT
GGT CGC ACT TT-3', nt 919-938). A full-length rGAS7 cDNA sequence containing an open reading frame was deduced from overlapping cDNA clones. Standard methods for screening, molecular cloning, plasmid construction, and DNA and probe preparations were performed as described elsewhere (Sambrook et al., 1989).

\section{Treatment of PC12 Cells With Oligonucleotides}

Cultured PC12 cells were treated with phosphorothioated rGas 7 antisense oligonucleotide (rGas7-As: the nucleotide sequence of $\mathrm{rGas} 7-\mathrm{As}$ is $5^{\prime}$-TCT CCT GGT GGA GGG GGG ACC ATC C-3') at a concentration of $6 \mu \mathrm{g} / \mathrm{ml}$ cultures. rGas 7-As was predicted to hybridize to the most likely translation-initiation region of $\mathrm{rGas} 7 \mathrm{mRNA}$ (nt 62-86). Control cultures were treated with the corresponding sense oligonucleotide (rGas7-S; 5'-GGA TGG TCC CCC CTC CAC CAG GAG A-3') under the same conditions. The sequences of these oligonucleotides did not match any known rat sequences in the GenBank database. Incubation of oligonucleotide-treated cell cultures continued for 3 days before immunocytochemical analysis, unless otherwise indicated in the figure legends.

\section{Microscopic Evaluation of Neurite Outgrowths}

PC12 cells were maintained according to supplier's instructions (American Type Culture Collection). Differentiation was stimulated by NGF (Upstate Biotechnology Inc.; catalog No. 01-170; $50 \mathrm{ng} / \mathrm{ml}$ culture) in freshly split overnight cultures grown on poly-L-lysine-precoated Petri dishes or microscopic glass coverslips. Cells stained with fluorescence-conjugated antibodies were examined under a fluorescence microscope. Cells with one or more neurite extensions of more than two cell body lengths were considered to be neurite positive. Precisely 300 cells from each dish were examined, and all experiments were conducted in duplicate.

\section{Detection of Endogenous rGas7 Expression in PC12 Cells by Western Blot Analysis}

Western blotting was carried out using standard methodology (Harlow and Lane, 1988). Briefly, cells were washed with ice-cold phosphate-buffered saline and resuspended in lysis buffer (150 mM NaCl, 1\% NP-40, 50 mM Tris, pH 8.0). After centrifugation, the supernatant was heated for $5 \mathrm{~min}$, separated on $10 \%$ SDS-PAGE, and analyzed by immunostaining using anti-mouse Gas7 antibody (Ju et al., 1998).

\section{RESULTS}

\section{Production of Gas7 Alone in PC12 Leads to Expanded Cell Shape With Spike-Like Cell Processes}

Previously, we reported that the overexpression of mouse Gas7 (mGas7) in a neuroblastoma cell line (Neuro 2A) induces neurite-like outgrowths from the cells (Ju et al., 1998). Here we investigate the effect of Gas7 in other cell types. mGas7 was overexpressed in PC12 cells when we used a plasmid expressing $m$ Gas7-EGFP recombinant fusion protein to facilitate the detection of neurite out-

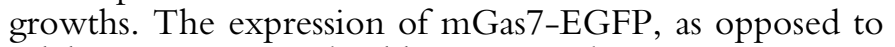
solely EGFP, reproducibly promoted extensive neurite 

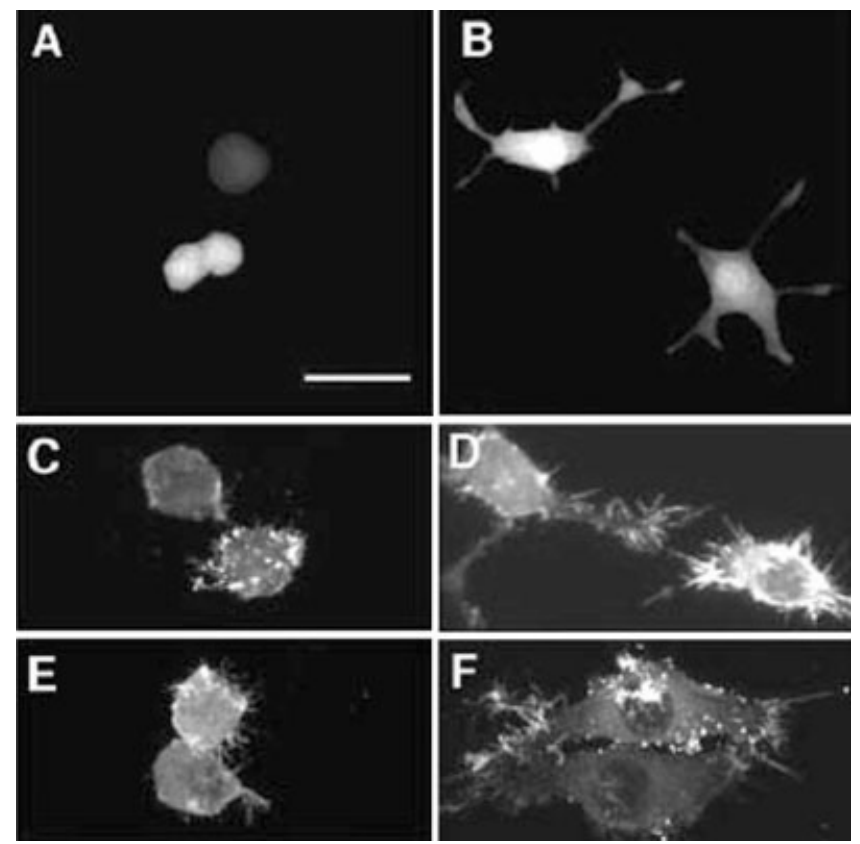

Fig. 1. Overexpression of Gas7-EGFP in PC12 cells. PC12 cells transfected with pEGFP or pmGas7-EGFP and incubated for $36 \mathrm{hr}$ in the presence $(\mathbf{B}, \mathbf{D}, \mathbf{F})$ or absence $(\mathbf{A}, \mathbf{C}, \mathbf{E})$ of NGF were examined with confocal microscopy. The formation of spike-like cell processes in PC12 cells in the absence of NGF was associated with the overexpression of Gas7-EGFP (C,E) but not EGFP alone (A). NGF-treated PC12 cells overexpressing Gas7-EGFP (D,F) display more elaborated cell processes than those overexpressing EGFP alone (B). Panels A-F are of equal magnification and were detected by autofluorescence emitted from the EGFP.

outgrowths in Neuro 2A cells (data not shown), indicating that the fusion protein was as fully functional as mGas7. Gas7 could be detected in PC12 cells at $24 \mathrm{hr}$ following transfection. However, neurite outgrowths were not seen until $36 \mathrm{hr}$. Interestingly, expression of the fusion protein in PC12 cells in the absence of NGF led to an expanded cell shape and spike-like cellular processes (Fig. 1C,E). These cellular processes were enhanced in both number and length with the addition of NGF (compare Fig. 1D,F with C,E). Furthermore, in all experiments shown, Gas7 localization was concentrated at the cell membrane where elongated outgrowths, spikes, and spike-clusters protruded (Fig. 1C-F), implicating Gas7 in the regulation of these cell processes.

\section{Endogenous rGas7 Induction in PC12 by NGF Begins Prior to the Appearance of Neurite Outgrowths}

Western blot analysis of endogenous Gas7 production in PC12 before and after the addition of NGF was subsequently performed. After treatment of PC12 cells by NGF at concentrations normally used to induce PC12 cell differentiation, a marked increase in rGas7 production was noted within $3 \mathrm{hr}$ posttreatment and lasted for at least
A

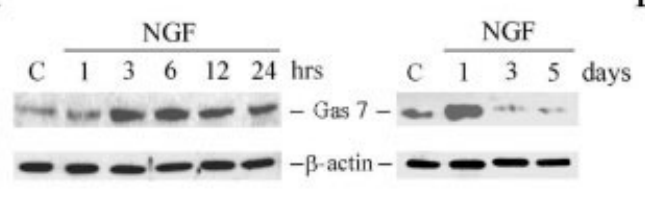

B

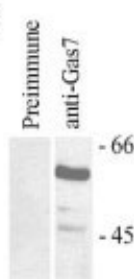

Fig. 2. Transient induction of rGas7 by NGF in PC12 cells. A: Induction of Gas7 protein in PC12 cells by NGF. Fifty-microgram protein extracts from cells treated with NGF for the indicated times were analyzed by immunoblot staining. Only the major Gas7 band $(\sim 60 \mathrm{kDa})$ is shown. Bottom panel shows the same gel stained with $\beta$-actin antibody. Size markers $(\mathrm{kDa})$ are indicated at left. B:) Fiftymicrogram protein extracts from PC12 cells treated with NGF $(50 \mathrm{ng} / \mathrm{ml})$ for $24 \mathrm{hr}$ analyzed by immunoblot staining using Gas7 antibody or preimmune serum. Size markers $(\mathrm{kDa})$ are indicated.

$24 \mathrm{hr}$ (Fig. 2A, left; only the predominant Gas7 species is shown, see Fig. 2B for other species). The level of rGas7 transiently increased by two- to four-fold on day 1 of treatment and declined to a basal level or below by day 3 (Fig. 2A, right). The induction of rGas7 in PC12 cells by NGF was specific and was not a result of variation in protein loading (Fig. 2A, bottom; a similar level of $\beta$-actin proteins was detected in each sample). In all experiments, a predominant species of $\sim 60-\mathrm{kDa}$ Gas7 isoform was detected; some lower level expression of other Gas7 isoforms was also detected by extended ECL detection (Fig. $2 \mathrm{~B}$; the protein sample was extracted from PC12 cells treated with NGF for $24 \mathrm{hr}$ ). Preimmune serum substituted for anti-mGas7 serum in Western blots failed to give any signal corresponding to rGAs7 (Fig. 2B).

Only trace amounts of endogenous rGas7 were detected by using immunofluorescence in NGF-untreated PC12 cells (Fig. 3B). However, immunofluorescent detection of endogenous rGas7 in NGF-treated PC12 cells revealed that intracellular induction of rGas7 occurs soon after the addition of NGF: rGas7 was induced to its maximum level of expression at $2-3 \mathrm{hr}$ post-NGF treatment and began to decline after 48-72 hr posttreatment (Fig. 3D,F,H). The appearance of cellular neurite outgrowths was detected $24 \mathrm{hr}$, but not $2 \mathrm{hr}$, post-NGF treatment. These results demonstrate that NGF-induced PC12 differentiation leads to a significant increase in production of rGas7 prior to the appearance of cellular neurite outgrowths (Fig. 3D). Gas7 expression was not induced by 200 ng/ml EGF (see Appendix), a physiological concentration that effectively activated the ERK signal pathway (data not shown). Collectively, these findings suggest that rGas7 may play a key role in the early stage of neurite formation in NGF-induced PC12 cell differentiation.

\section{Requirement of rGas7 for Neurite Formation in NGF-Induced PC12 Cell Differentiation}

To assess whether rGas7 indeed plays a key role in the neurite formation of NGF-treated PC12 cells, a specific rGas 7 antisense oligonucleotide complimentary to 


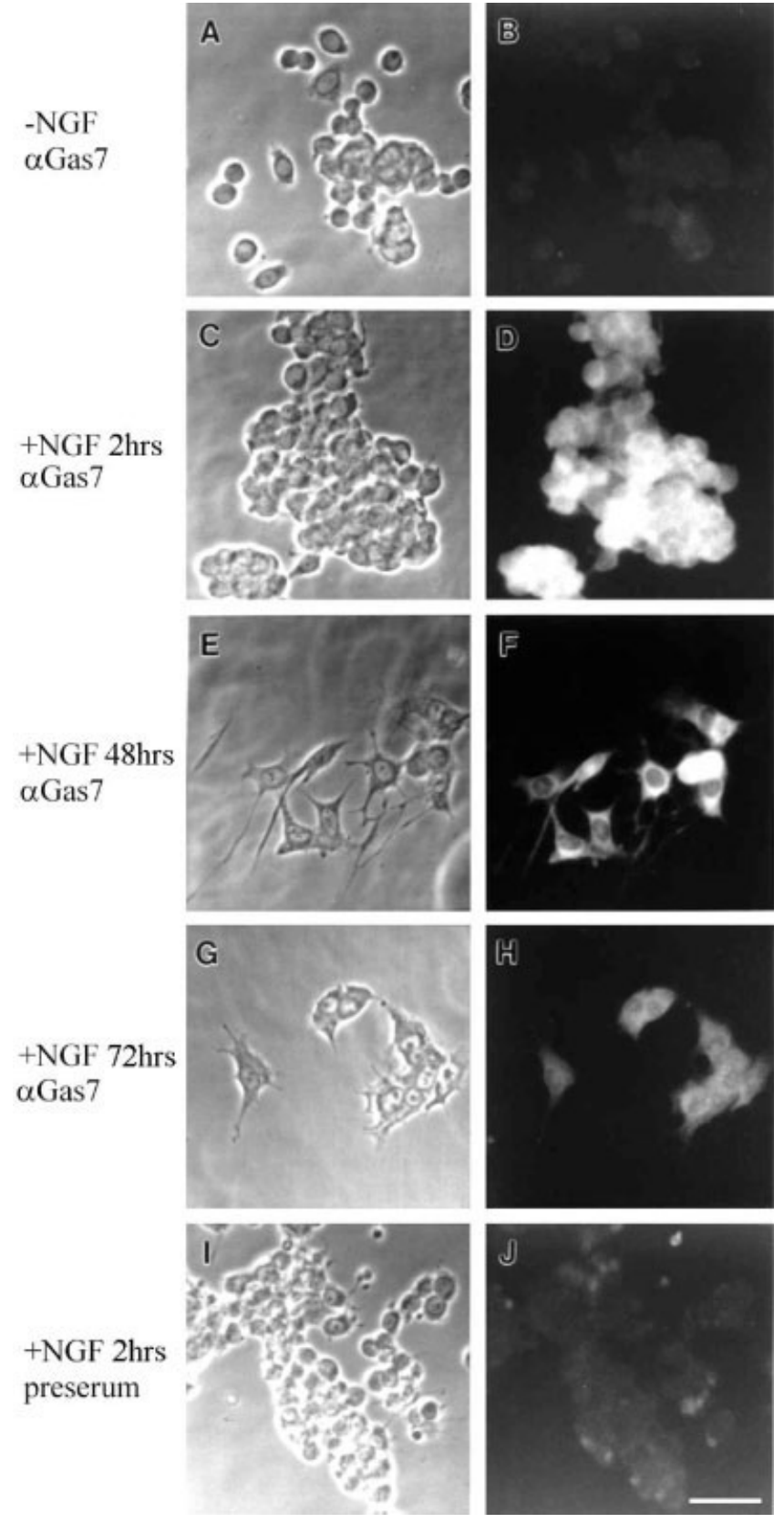

Fig. 3. Immunofluorescence microscopy of endogenous rGas7 protein in PC12 cells with or without addition of NGF. PC12 cells without addition of NGF (B), with addition of NGF for 2-3 hr (D), $48 \mathrm{hr}(\mathbf{F})$, and $72 \mathrm{hr}(\mathbf{H})$ were detected by anti-Gas7 antibodies. $\mathbf{J}$ : A duplicate PC12 culture of that shown in C; instead of anti-Gas7 antiserum, the preimmune serum for analysis. The endogenous production of rGas7 was positively revealed by the Gas7 antiserum but not preimmune serum (compare D and J), demonstrating that positive staining of Gas7 was specific. The individual phase-contrast fields of the right panels are also shown (A,C,E, G,I), respectively. Scale bar $=80 \mu \mathrm{m}$. the $5^{\prime}$-end terminus near the translation initiation region was used to block rGas7 expression. To verify the nucleotide sequences, we cloned and characterized rGas 7 cDNA from a neocortex expression library by DNA hybridization using mouse Gas 7 as a probe (see Materials and Methods for details). A full-length rGas 7 cDNA sequence (EMBL/GenBank/DDBJ accession No. AJ131902) was deduced from overlapping cDNA clones consisting of two conserved Kozak domains: GCCATGA and GGGATGG, located at nt 77 and 161 (the fourth in-phase AUG), respectively, 28 amino acids (aa) apart. The hexanucleotide sequence AGAAGC, which is commonly present $5^{\prime}$ to the translation start site of mammalian cell mRNA (Kozak, 1991), occurs only at the fourth in-phase AUG codon. The cDNA also contains a polyadenylation AATAAA domain $19 \mathrm{nt}$ upstream of the poly-(A). The protein sequence alignments of Gas7 from rat, mouse (accession No. U19860), and human (accession No. AB007854) show approximately 97\% homology. The amino-terminus of rGas7 has an 28 additional amino acids compared with that of mouse Gas7 and 19 additional amino acids compared with that of human GAS7. rGas7 also contains a glutamic acid at residue 295 that is absent from both mouse and human Gas7.

To assess whether rGas7 is required in neurite formation in NGF-treated PC12 cells, the specific rGas 7 antisense oligonucleotide complimentary to the translation initiation region (nt 62-86) of rGas 7 cDNA was used to block rGas7 expression in PC12 cells in experiments involving the addition of NGF. Pretreatment of cells for $24 \mathrm{hr}$ with $6 \mu \mathrm{g} / \mathrm{ml}$ of the antisense was sufficient to inhibit the expression of all rGas7 isoforms in 24-hr NGFtreated cells (Fig. 4A). Six micrograms per milliliter of antisense oligonucleotide was used for subsequent experiments. PC12 cells were pretreated with sense or antisense rGas 7 oligonucleotides for $24 \mathrm{hr}$ prior to the addition of NGF. Western blot analysis was carried out in parallel to monitor the inhibition of Gas7 expression by the addition of antisense oligonucleotide. We found that blockage of rGas7 expression by rGas7 antisense was effective for at least 4 days in experiments involving the addition of NGF (Fig. 4B). Precisely 300 cells from each dish were examined, and all experiments were conducted in duplicate. Eighty percent of PC12 cells treated with NGF but without oligonucleotides, examined 4 days after the addition of NGF, displayed neuritis, with most of these cells displaying two or more neurites (Fig. 4Cb). In NGF-treated cells pretreated with sense oligonucleotide for $24 \mathrm{hr}$, results were very similar to those with cells treated with only NGF (Fig. 4Cd vs. b). In NGF-treated cells pretreated with antisense $\mathrm{rGas} 7$ for $24 \mathrm{hr}$, only about $50 \%$ of cells displayed neurites (Fig. 4Cc). To show that antisense oligos attenuate NGF effects, the microscopic pictures are included (Fig. 4D). These results demonstrated that pretreatment of NGF-treated cells with antisense rGas7 caused greater inhibition of neurite formation than did pretreatment or no treatment with sense Gas 7, suggesting 
A

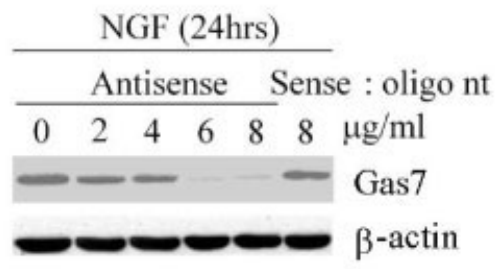

B

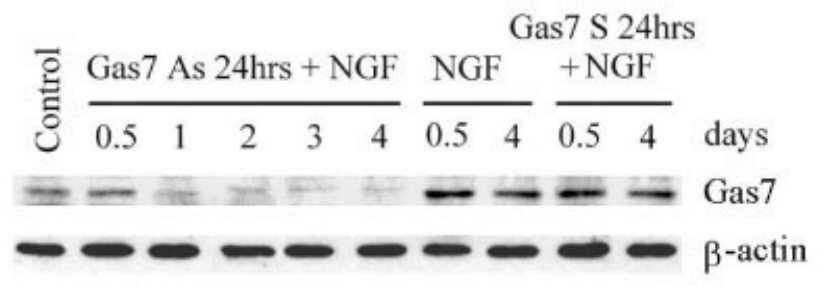

C
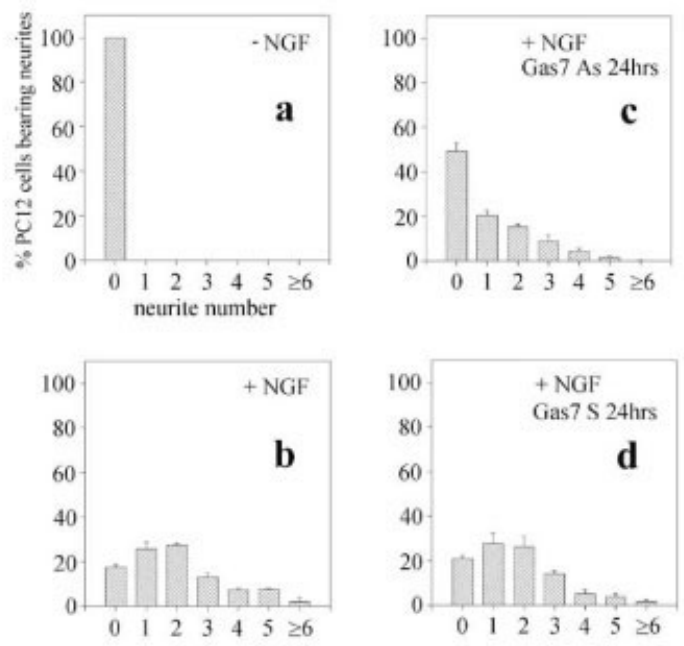

D
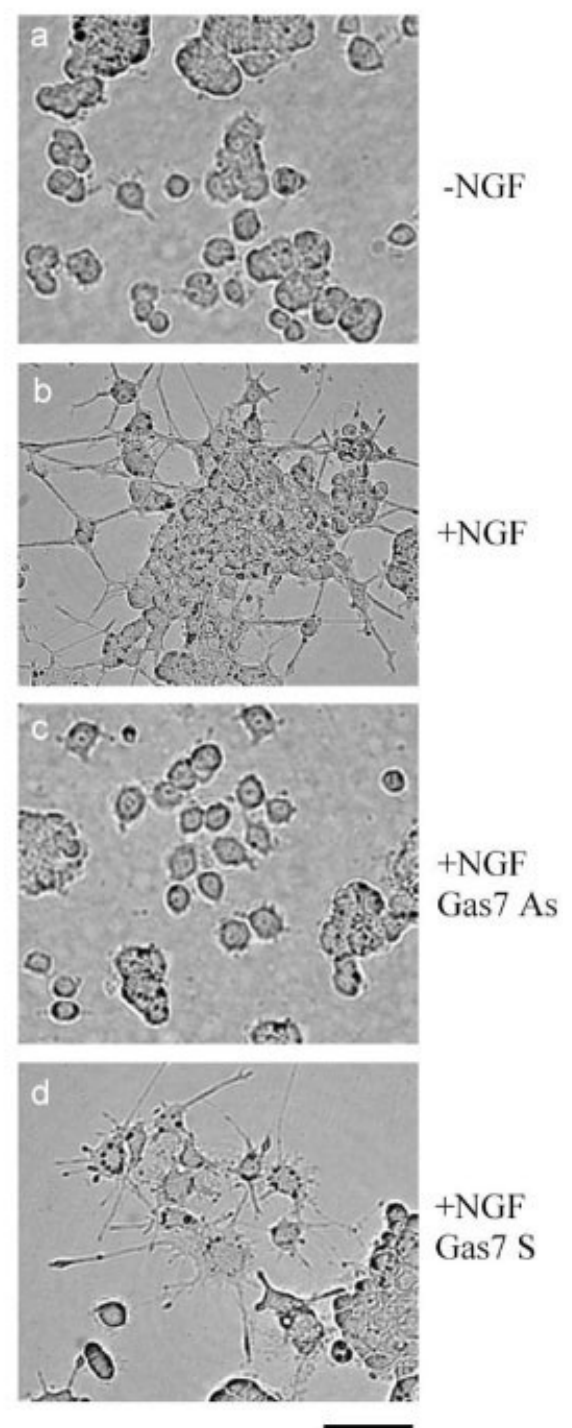

Fig. 4. Inhibition of neurite outgrowths in PC12 cells by antisense Gas 7 oligonucleotide. A: Induction of Gas7 by NGF in the presence of antisense or sense Gas 7 oligonucleotide at the indicated concentrations. Cells were treated with oligonucleotides for $24 \mathrm{hr}$ before addition of NGF. Top panel shows a typical immunoblotting. Bottom panel shows the same gel stained with $\beta$-actin antibody. B: Inhibition of NGFinduced Gas7 in the presence of antisense or sense Gas 7 oligonucleotides at indicated time periods. Gas 7 antisense oligonucleotides (Gas7 As) or sense oligonucleotides (Gas7 S) at $6 \mu \mathrm{g} / \mathrm{ml}$ were used for induction. C: Inhibition of NGF-induced neurite outgrowths in PC12 cells by antisense Gas 7 oligonucleotides. PC12 cells were induced for neurite outgrowths by NGF, with sense or antisense Gas 7 oligonucleotides $(6 \mu \mathrm{g} / \mathrm{ml})$, incubated for $24 \mathrm{hr}$ prior to the addition of NGF, and detected 4 days after NGF addition. The data indicate the average (with $\mathrm{SD})$ of 300 cells from each dish conducted in duplicate. D: Cell morphology. PC12 cells with indicated treatment were revealed by phase-contrast microscopy. Scale bar $=80 \mu \mathrm{m}$. that rGas7 is required for efficient induction of NGFmediated neurite formation in PC12 cells.

\section{DISCUSSION}

Under normal culture conditions, the rat PC12 cell line shows characteristics similar to those of endocrine cells. When treated with NGF, these cells begin to differentiate into neuron-like cells bearing prominent cell pro- cesses (Green et al., 1976). In the present study, we found that production of one of the Gas7 isoforms alone in PC12 cells, without the addition of NGF, sufficiently promotes an expanded cell shape with spike-like processes. Although the spike-like outgrowths in PC12 cells with Gas7 alone were not as pronounced as those in Neuro 2A cells (Ju et al., 1998), Gas7 still localized at the membrane predominantly at points of protrusion. Overexpression of 


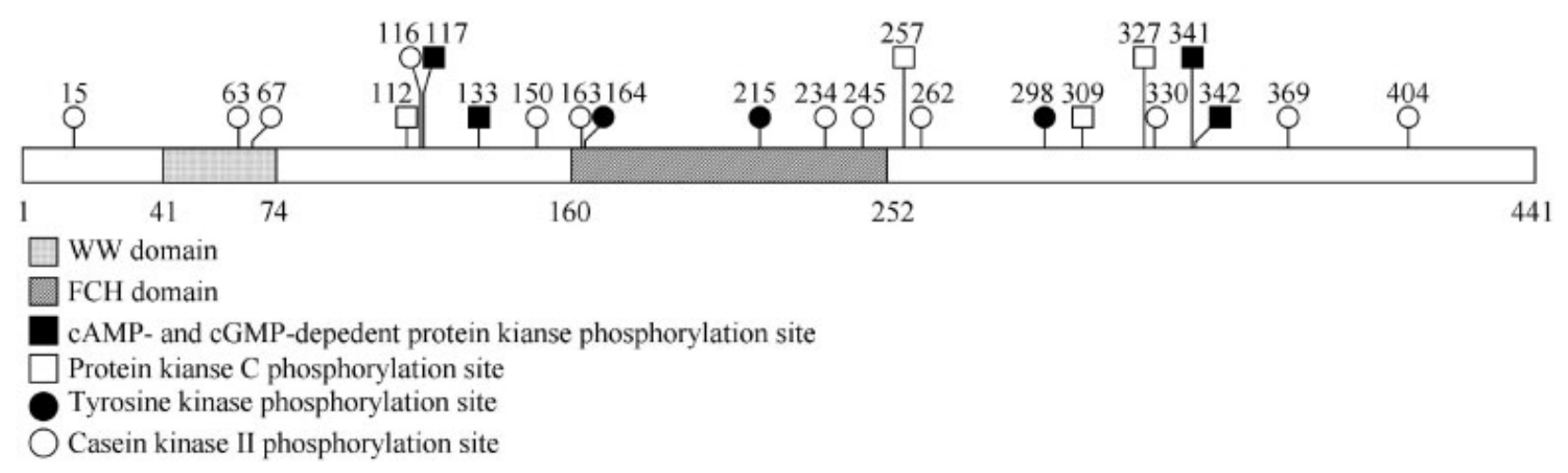

Fig. 5. Putative phosphorylation sites of rat Gas7 and regions that share sequence homology with other genes.

Gas7 also induces spike-like outgrowths in NIH3T3 fibroblasts (She et al., 2002), suggesting that Gas7 involvement in cell processes may be not limited to neural cell types. The unique localization of Gas7 and its more specific role in cell processes remain to be investigated. However, we have found that Gas 7 is required for NGFmediated neurite outgrowths by showing that Gas7 is induced at an early stage of NGF-mediated PC12 differentiation and that knockout of Gas7 production impedes neurite formation. Collectively, these results suggest that Gas7 most likely plays a role at an early stage of cell process development in various cell types.

Gas7 isoforms in the range of 45-65 kDa were detected in rat and mouse brain tissues (Ju et al., 1998), and preferential expression of the isoforms has been observed in different regions of mouse brain (Lazakovitch et al., 1999). In the present study, a predominant species of Gas7 larger than other Gas7 isoforms observed in brain tissues was detected in PC12 cells, suggesting a preferential expression of Gas 7 in other tissues as well as neural cells. Indeed, this larger Gas7 species was also detected predominantly in an extract prepared from mouse kidney with intact adrenal gland (data not shown). In which cell type(s) and by what mechanisms this species is produced predominantly in tissues other than brain tissues, and the specific role(s) of Gas 7 in those tissues, remain to be investigated.

The sequence of rat Gas7 has been submitted to the GenBank database (EMBL/GenBank/DDBJ accession No. AJ131902). With a computer program (NiceProt View of Swiss-Prot), a WW domain and an FCH domain were predicted for the Gas7 protein sequence (O55148; Fig. 5). Mouse and human Gas7 share the same structural features because of a 98\% homology of the full-length Gas7 open reading frame sequence. Many proteins containing an $\mathrm{FCH}$ domain are involved in the regulation of cytoskeletal rearrangement, for example, CIP4 and rapostlin, which bind to microtubules (Tian et al., 2000; Fujita et al., 2002), and dystrophin, which consists of an N-terminal actin-binding domain (Ilsley et al., 2002). The physical assignment of the Gas7 to the analog of WW and FCH domain proteins supports a potential involvement of Gas7 in neurite plasticity and associated cytoskeleton re- modeling. Additionally, Gas7 contains numerous potential protein kinase sites. Because the WW domain frequently is associated with other domains typical for proteins in signal transduction processes (Ilsley et al., 2002), the role of Gas7 in cell process formation, particularly neurite outgrowth can be regulated by phosphorylation during cytoskeletal rearrangement.

NGF-induced neurite outgrowths in PC12 cells are also known to be involved in the coordinated induction of other cellular components, e.g., microtubule assembly and assembly-promoting factors, including certain microtubuleassociated proteins (MAPs; Brugg and Matus, 1988; for review see Kobayashi and Mundel, 1998). Overexpression of some, but not all, MAPs alone can induce the formation of microtubule-based cell processes in nonneuronal cells, such as fibroblasts (Kanai et al. 1989). However, unlike the case with Gas7, the expression of MAPs by themselves is not sufficient for the induction of cell processes in PC12 cells, which requires additional NGF-mediated intracellular signals (Cowley et al., 1994; Kaplan and Miller, 1997) to initiate the formation of cell processes. Interestingly, as in PC12 cells, Gas7 overproduction in fibroblasts also causes pronounced cell processes (She et al., 2002). Biochemical studies and electron microscopy showed that both full-length Gas7 protein and its C-terminal region can promote actin assembly as well as the cross-linking of actin filaments (She et al., 2002). The relationship of Gas7 and MAPs and/or other cytoskeletal elements activated by NGF is worthy of further study, and the role of Gas7 in the cell differentiation of both neuronal and nonneuronal cell types continues to be a fundamental issue in understanding cell process development.

\section{ACKNOWLEDGMENTS}

We thank Dr. S.N. Cohen for helpful comments and suggestions; Dr. H.-L. Wang for rat brain cDNA library; C.-L. Lien, C.-H. Liu, and W.-L. Su for assistance in plasmid constructions and sequencing; and H.-P. Lu for preparing figures. This study was supported by The Foundation for the Advancement of Outstanding Scholarship to C.C.-K.C. and by Academia Sinica and the National Science Council, R.O.C. (grants NSC87-2312-B001-017 and 89-2312-B001-002) to S.L.-C. 


\section{APPENDIX}

\section{A}
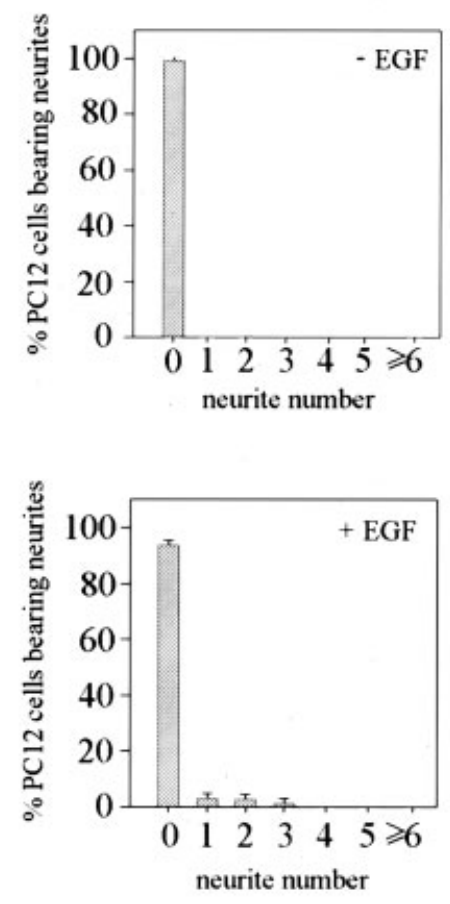

B

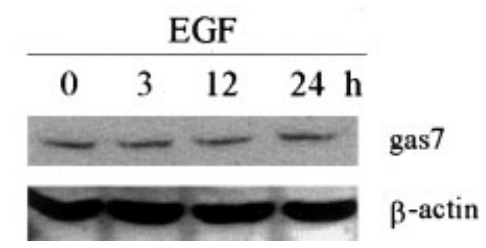

\section{REFERENCES}

Adlkofer K, Martini R, Aguzzi A, Zielasek J, Toyka KV, Suter U. 1995. Hypermyelination and demyelinating peripheral neuropathy in Pmp22deficient mice. Nat Genet 11:274-280.

Brancolini C, Bottega S, Schneider C. 1992. Gas2, a growth arrest-specific protein, is a component of the microfilament network system. J Cell Biol 117:1251-1261.

Brenner DG, Lin-Chao S, Cohen SN. 1989. Analysis of mammalian cell genetic regulation in situ by using retrovirus-derived "portable exons" carrying the Escherichia coli lacZ gene. Proc Natl Acad Sci USA 86:5517-5521.

Brugg B, Matus A. 1988. PC12 cells express juvenile microtubuleassociated proteins during nerve growth factor-induced neurite outgrowth. J Cell Biol 107:643-650.

Cowley S, Paterson H, Kemp P, Marshall CJ. 1994. Activation of MAP kinase kinase is necessary and sufficient for PC12 differentiation and for transformation of NIH 3T3 cells. Cell 77:841-852.

Del Sal G, Collavin L, Ruaro ME, Saccone S, Della Valle G, Schneider C. 1994. Structure, function, and chromosome mapping of the growth- suppressing human homologue of the murine gas1 gene. Proc Natl Acad Sci USA. 91:1848-1852.

Fabbretti E, Edomi P, Brancolini C, Schneider C. 1995. Apoptotic phenotype induced by overexpression of wild-type gas3/PMP22: its relation to the demyelinating peripheral neuropathy CMT1A. Genes Dev 9:1846-1856.

Frohman MA. 1990. In: Innis MA, Gelfand DH, Snindky JJ, White TJ, editors. PCR protocol: a guide to methods and applications. San Diego. Academic Press. 28-38.

Fujita H, Katoh H, Ishikawa Y, Mori K, Negishi M. 2002. Rapostlin is a novel effector of Rnd2 GTPase inducing neurite branching. J Biol Chem 277:45428-45434.

Green LA, Tischler AS. 1976. Establishment of a noradrenergic clonal line of rat adrenal pheochromocytoma cells which respond to nerve growth factor. Proc Natl Acad Sci USA 73:2424-2428.

Harlow E, Lane D. 1988. Antibodies: a laboratory manual. Cold Spring Harbor, NY. Cold Spring Harbor Laboratory.

Ilsley JL, Sudol M, Winder SJ. 2002. The WW domain: linking cell signaling to the membrane cytoskeleton. Cell Signal 14:183-189.

Ju Y-T, Chang ACY, She B-R, Tsaur M-L, Hwang H-M, Chao CC.-K, Cohen SN, Lin-Chao S. 1998. Gas7: a gene expressed preferentially in growth-arrested fibroblasts and terminally differentiated Purkinje neurons affects neurite formation. Proc Natl Acad Sci USA 95:11423-11428.

Kanai Y, Takemura R, Oshima T, Mori H, Ihara Y, Yanagisawa M, Masaki T, Hirakawa N. 1989. Expression of multiple tau isoforms and microtubule bundle formation in fibroblasts transfected with a single tau cDNA. J Cell Biol 109:1173-1184.

Kaplan DR, Miller FD. 1997. Signal transduction by the neurotrophin receptors. Curr Opin Cell Biol 9:213-221.

Kobayashi N, Mundel P. 1998. A role of microtubules during the formation of cell processes in neuronal and non-neuronal cells. Cell Tissue Res 291:163-1749.

Kozak M. 1991. Structural features in eukaryotic mRNAs that modulate the initiation of translation. J Biol. Chem 266:19867-19870.

Lazakovitch EM, She B-R, Lien C-L, Woo W-M, Ju Y-T, Lin-Chao S. 1999. The Gas7 gene encodes two protein isoforms differentially expressed within the brain. Genomics 61:298-306.

Li R, Chen J, Hammonds G, Phillips H, Armanini M, Wood P, Bunge R, Godowski PJ, Sliwkowski MX, Mather JP. 1996. Identification of Gas6 as a growth factor for human Schwann cells. J Neurosci 16:2012-2019.

Lih C-J, Cohen SN, Wang C, Lin-Chao S. 1996. The platelet-derived growth factor alpha-receptor is encoded by a growth-arrest-specific (gas) gene. Proc Natl Acad Sci USA 93:4617-4622.

Magyar JP, Martini R, Ruelicke T, Aguzzi A, Adlkofer K, Dembic Z, Zielasek J, Toyka KV, Suter U. 1996. Impaired differentiation of Schwann cells in transgenic mice with increased PMP22 gene dosage. J Neurosci 16:5351-5360.

Manfioletti G, Ruaro ME, Del Sal G, Philipson L, Schneider C. 1990. A growth arrest-specific (gas) gene codes for a membrane protein. Mol Cell Biol 10:2924-2930.

Saiki RK, Gelfand DH, Stoffel S, Scharf SJ, Higuchi R, Horn GT, Mullis KB, Erlich HA. 1988. Primer-directed enzymatic amplification of DNA with a thermostable DNA polymerase. Science 239:487-491.

Sambrook J, Fritsch EF, Maniatis T. 1989. Molecular cloning: a laboratory manual. Cold Spring Harbor, NY. Cold Spring Harbor Laboratory.

Schneider C, King RM, Philipson L. 1988. Genes specifically expressed at Growth arrest of mammalian cells. Cell 54:787-793.

She BR, Liou GG, Lin-Chao S. 2002. Association of the growth-arrestspecific protein Gas7 with F-actin induces reorganization of microfilaments and promotes membrane outgrowth. Exp Cell Res 273:34-44.

Tian L, Nelson DL, Stewart DM. 2000. Cdc42-interacting protein 4 mediates binding of the Wiskott-Aldrich syndrome protein to microtubules. J Biol Chem 275:7854-7861.

Zoidl G, Blass-Kampmann S, D’Urso D, Schmalenbach C, Muller HW. 1995. Retroviral-mediated gene transfer of the peripheral myelin protein PMP22 in Schwann cells: modulation of cell growth. EMBO J 14:1122-1128. 